\title{
Randomized Double Blind Controlled Study Comparing Vecuronium Priming, Magnesium Pretreatment and Combination of the Two Methods on the Onset of Intubating Conditions
}

\author{
Dr. Nalini K B ${ }^{1}$, Dr. Shazia Ambareen ${ }^{2}$, Dr. Mohan C V R $\mathbf{R}^{3}$ \\ ${ }^{1}$ Assistant Professor, Department of Anaesthesiology, M S Ramaiah Medical College, Bangalore, India \\ ${ }^{2}$ Junior Resident, Department of Anaesthesiology, M S Ramaiah Medical College, Bangalore, India \\ ${ }^{3}$ Professor and HOD Department of Anaesthesiology, M S Ramaiah Medical College, Bangalore, India
}

\begin{abstract}
Introduction: Priming markedly shortens the onset time to non depolarising neuromuscular blocking drugs. Magnesium inhibits presynaptic acetylcholine release at the motor end plate; hence magnesium potentiates the effect of non-depolarising muscle relaxants and shortens their onset time. Thus, the combination of priming and magnesium pre-treatment may be an alternative, effective method for accomplishing early tracheal intubation. We investigated whether magnesium sulphate with vecuronium priming shortens the onset of neuromuscular blockade, compared with these methods used alone. Materials and Methods: 100 patients undergoing elective surgical procedures under general anaesthesia were randomized into group $N(n=25)$ were given $0.1 \mathrm{mg} / \mathrm{kg}$ vecuronium, group $V(n=25)$ were primed with $0.01 \mathrm{mg} / \mathrm{kg}$ vecuronium three minutes before a further dose of $0.09 \mathrm{mg} / \mathrm{kg}$ vecuronium, group $M(\mathrm{n}=25)$ were given an infusion of $50 \mathrm{mg} / \mathrm{kg}$ magnesium sulphate before vecuronium, group $M V(n=25)$ were given both the magnesium sulphate and the priming dose of vecuronium. Trachea was intubated when the TOF stimulus showed only one twitch measured at intervals of 30 seconds. The time to onset of neuromuscular blockade, duration of blockade and tracheal intubating conditions were measured. Results: The magnesium and prime group had the shortest mean $(S D)$ onset time $112.80(19.89)$ sec $(p<0.001)$ compared to the other groups. The duration of blockade was prolonged in both Group $M$ and Group $M V(P<0.001)$. Few adverse effects were reported in magnesium preloaded group, clinically not significant. Conclusion: The combination of magnesium sulphate and vecuronium priming accelerated the onset of neuromuscular blockade compared with either magnesium sulphate or priming used alone.
\end{abstract}

Keywords: Vecuronium priming, magnesium sulphate, train of four, neuromuscular blockade

\section{Introduction}

Vecuronium is a non-depolarising neuromuscular blocking drug, which has minimal cardiovascular effects and lack of dependence on the kidney for elimination (1). But it has a disadvantage of having a relatively slow onset time, around 2-3 minutes with $0.1 \mathrm{mg} / \mathrm{kg}$ dose of vecuronium.

Magnesium inhibits presynaptic acetylcholine release at the motor end plate and acts as a minor calcium antagonist on the muscle itself. As a result, magnesium has been reported to potentiate the effect of non-depolarising muscle relaxants and could shorten their onset time $(2,3)$.

Priming principle refers to administration of small, sub paralysing dose of non depolarising neuromuscular blocking drug several minutes before the intubating dose is given. The hypothesis is that this approach will markedly shorten the onset time to non depolarising neuromuscular blocking drugs $(4,5)$.

Thus, the combination of priming and magnesium pretreatment may be an alternative, effective method for accomplishing early tracheal intubation. There are studies with rocuronium priming and magnesium pretreatment (6). In this study we tested the hypothesis that combination of priming with vecuronium and magnesium pretreatment is an effective method in achieving early ideal intubating conditions.

\section{Materials and Methods}

This was a prospective, randomized double blind controlled study. After obtaining institute ethics committee clearance, study was undertaken in M S Ramaiah hospital. A total of 100 patients scheduled to undergo elective surgery under general anaesthesia were recruited for the study. Inclusion criteria - age range 18 - 65yrs, American society of Anaesthesiologists (ASA) physical status I-II, mallampati class1-2. Exclusion criteria anticipated difficult airway, reactive airway disease, allergic to study drugs, risk of pulmonary aspiration, neuromuscular/ cardiovascular/renal/hepatic disease, body mass index (BMI) $<18.5$ or $>24.9 \mathrm{~kg} / \mathrm{m} 2$, chronic treatment with calcium channel blockers and medication which affect muscle relaxation. Informed consent was taken from the included patients. Patients were randomized using a computer generated random number table into four groups.

All patients were kept nil per oral on the previous night and were premedicated with oral ranitidine $150 \mathrm{mg}$ and ondansetron $8 \mathrm{mg}$ in the night and 2 hours before surgery. Glycopyrolate $0.2 \mathrm{mg}$ intramuscularly was given half an hour before shifting to operation theatre (OT). On arrival to OT standard monitoring included Electrocardiogram (ECG), 


\section{International Journal of Science and Research (IJSR) \\ ISSN (Online): 2319-7064 \\ Index Copernicus Value (2013): 6.14 | Impact Factor (2014): 5.611}

Non invasive blood pressure, end tidal carbon dioxide and pulse oximetry. Train of four (TOF) watch was connected to the ulnar nerve at the wrist on the opposite side of blood pressure cuff.

Group N ( $\mathrm{n}=25)$ : Patients received $100 \mathrm{ml}$ normal saline as intravenous infusion over $10 \mathrm{~min}$. At $7^{\text {th }}$ minute of infusion, after pre-oxegenation, general anaesthesia (GA) was induced with midazolam $0.025 \mathrm{mg} / \mathrm{kg}$, fentanyl $2 \mu \mathrm{g} / \mathrm{kg}$ and thiopentone $5 \mathrm{mg} / \mathrm{kg}$. At the $10^{\text {th }}$ minute, after the completion of infusion, vecuronium $0.1 \mathrm{mg} / \mathrm{kg}$ was administered. Train of Four (TOF) stimulus was monitored every 30 seconds. Endotracheal intubation was performed at the point were a single twitch was recorded on the TOF.

Group V ( $\mathrm{n}=25)$ : Patients received $100 \mathrm{ml}$ normal saline as intravenous infusion over $10 \mathrm{~min}$. At $7^{\text {th }}$ minute of infusion, a priming dose of vecuronium $0.01 \mathrm{mg} / \mathrm{kg}$ was administered followed by induction of GA with midazolam $0.025 \mathrm{mg} / \mathrm{kg}$, fentanyl $2 \mu \mathrm{g} / \mathrm{kg}$ and thiopentone $5 \mathrm{mg} / \mathrm{kg}$. At the $10 \mathrm{th}$ minute, after the completion of infusion, vecuronium 0.09 $\mathrm{mg} / \mathrm{kg}$ was administered. TOF stimulus was monitored every 30 seconds. Endotracheal intubation was performed at the point were a single twitch was recorded on the TOF.

Group $\mathrm{M}(\mathrm{n}=25)$ : patients received $100 \mathrm{ml}$ normal saline with magnesium sulphate $50 \mathrm{mg} / \mathrm{kg}$ as intravenous infusion over $10 \mathrm{~min}$. At $7^{\text {th }}$ minute after commencement of infusion, after pre-oxygenation, GA was induced with midazolam $0.025 \mathrm{mg} / \mathrm{kg}$, fentanyl $2 \mu \mathrm{g} / \mathrm{kg}$ and thiopentone $5 \mathrm{mg} / \mathrm{kg}$. At the 10th minute, after the completion of infusion, vecuronium $0.1 \mathrm{mg} / \mathrm{kg}$ was administered. TOF stimulus was monitored every 30 seconds. Endotracheal intubation was performed at the point were a single twitch was recorded on the TOF.

Group MV ( $\mathrm{n}=25)$ : All patients received $100 \mathrm{ml}$ normal saline with magnesium sulphate $50 \mathrm{mg} / \mathrm{kg}$ as intravenous infusion over $10 \mathrm{~min}$. At $7^{\text {th }}$ minute of infusion, a priming dose of vecuronium $0.01 \mathrm{mg} / \mathrm{kg}$ was administered followed by induction of GA with midazolam $0.025 \mathrm{mg} / \mathrm{kg}$, fentanyl $2 \mu \mathrm{g} / \mathrm{kg}$ and thiopentone $5 \mathrm{mg} / \mathrm{kg}$. At the $10 \mathrm{th}$ minute, after the completion of infusion, vecuronium $0.09 \mathrm{mg} / \mathrm{kg}$ was administered. TOF stimulus was monitored every 30 seconds. Endotracheal intubation was performed at the point when a single twitch was recorded on the TOF.

Intubation conditions was assessed using the train of four stimuli, when only one twitch is present tracheal intubation was attempted. Intubating conditions will be scored as excellent (8-9), good (6-7), fair (3-5), and poor (0-2) according to a system described by Cooper.

\begin{tabular}{|c|c|c|c|}
\hline Ccore & Jaw relaxation & Vocal cords & $\begin{array}{c}\text { Response to } \\
\text { intubation }\end{array}$ \\
\hline 0 & Impossible to open & Closed/bucking & Severe coughing \\
\hline 1 & $\begin{array}{c}\text { Opens with } \\
\text { difficulty }\end{array}$ & Closing & Mild coughing \\
\hline 2 & Moderate opening & Moving & $\begin{array}{c}\text { Slight } \\
\text { diaphragmatic } \\
\text { movement }\end{array}$ \\
\hline 3 & Easy opening & Open & No movement \\
\hline
\end{tabular}

Trachea was intubated using a suitable size endotracheal tube. Anaesthesia was maintained with isoflurane $1 \%$ in oxygen and air. After an effective tracheal intubation, every 5 minutes train of four stimulation was recorded. Onset of neuromuscular blockade was calculated from the time of injection of vecuronium to the time when only one twitch is present on TOF stimulation. The duration of neuromuscular block was calculated from time of administration of vecuronium to the time when fourth twitch reappears. Any side effects like (flushing, dysphagia, weakness) were recorded.

\section{Statistics}

Sample size was estimated on the basis of previous published study in which the onset of neuromuscular block by using vecuronium was $156 \pm 12$ seconds (mean \pm standard error of mean), and using vecuronium priming was $61 \pm 3$ seconds (mean \pm standard error of mean). For the present study around 23 subjects in each group will be required to get similar results with a precision of $95 \%$ confidence, $80 \%$ power and expecting 20 seconds difference as clinically significant. Therefore, minimum 25 patients per group were enrolled for possible dropouts.

The primary outcome was the time to onset of neuromuscular blockade. Secondary outcome were intubating conditions, the duration of neuromuscular blockade and side effects. Analysis of variance (ANOVA) has been used to find the significance of study parameters between three or more groups of patients, Post-Hoc Tukey test has been used to find the pairwise significance. Chisquare/ Fisher Exact test has been used to find the significance of study parameters on categorical scale between two or more groups. $\mathrm{P}<0.05$ was considered significant. The Statistical software SPSS 15.0 was used for the analysis of the data.

\section{Results}

Demographic data was comparable among groups (table1). Types of Surgery in four groups of patients studied were also comparable. Majority of the patients underwent ENT surgery $50 \%$ patients, followed by general surgery $22 \%$ (figure 1)

Onset of time was shortest for group MV (112.80 \pm 19.89 mean $\pm \mathrm{SD}$ ) compared to the other groups (Table 2). This was statistically significant compared to all groups except for Group M. Reappearance of $4^{\text {th }}$ twitch was prolonged in both Group M and MV (Table 2). Intergroup comparison for onset time and reappearance of $4^{\text {th }}$ twitch ( $\mathrm{min}$ ) were statistically significant between all the groups except for between Group M and Group MV (table 3).

Cooper score in four groups of patients studied. All patients had cooper score of $8-9(\mathrm{P}=1.000)$. Side effects in four groups of patients studied (figure 2). None of the patients in control and prime group had side effects. $6(24 \%)$ patients in magnesium group and $3(12 \%)$ patients in magnesium plus prime group experienced flushing, $2(8 \%)$ patients in magnesium group and $3(12 \%)$ patients in magnesium plus prime group experienced generalized weakness. 1(4\%) 


\section{International Journal of Science and Research (IJSR) \\ ISSN (Online): 2319-7064}

Index Copernicus Value (2013): 6.14 | Impact Factor (2014): 5.611

patient in in magnesium plus prime group experienced mild dysphagia. Though the side effects were statistically

significant, but clinically they were not significant.

Table 1: Demographic data

\begin{tabular}{|c|c|c|c|c|c|}
\hline Variables & Group $N(n=25)$ & Group V $(n=25)$ & Group $M(n=25)$ & Group $M V(n=25)$ & $P$ \\
\hline Age (years) mean \pm SD & $34.12 \pm 12.62$ & $38.00 \pm 15.14$ & $34.44 \pm 12.91$ & $35.52 \pm 12.58$ & 0.730 \\
\hline Male:Female & $13: 12$ & $14: 15$ & $9: 16$ & $8: 17$ & 0.239 \\
\hline ASA I:II & $22: 23$ & $17: 8$ & $17: 8$ & $18: 7$ & 0.316 \\
\hline Weight $(\mathrm{kg})$ Mean \pm SD & $56.84 \pm 7.44$ & $58.44 \pm 5.92$ & $55.24 \pm 4.44$ & $55.04 \pm 5.23$ & 0.147 \\
\hline
\end{tabular}

Table 2: onset time for intubation and reaapearnce of $4^{\text {th }}$ twitch

\begin{tabular}{|c|c|c|c|c|c|}
\hline & Group $N$ & Group V & Group M & Group MV & $P$ \\
\hline Onset time (seconds) Mean \pm SD & $222.00 \pm 30.00$ & $200 \pm 30.89$ & $128.40 \pm 25.27$ & $112.80 \pm 19.89$ & $<0.001$ \\
\hline Reappearance of $4^{\text {th }}$ twitch (min) Mean \pm SD & $40.20 \pm 10.94$ & $49.20 \pm 11.15$ & $76.40 \pm 9.41$ & $76.20 \pm 8.69$ & $<0.001$ \\
\hline
\end{tabular}

Table 3: $\mathrm{P}$ value between the groups

\begin{tabular}{|c|c|c|c|c|c|c|}
\hline & Group Nvs V & Group Nvs M & Group Nvs MV & Group Vvs $M$ & Group Vvs MV & Group Mvs MV \\
\hline Onset time ( P) & 0.028 & $<0.001$ & $<0.001$ & $<0.001$ & $<0.001$ & 0.175 \\
\hline $\begin{array}{c}\text { Reappearance of 4 } \\
\text { twitch (P) }\end{array}$ & 0.012 & $<0.001$ & $<0.001$ & $<0.001$ & $<0.001$ & 1.000 \\
\hline
\end{tabular}

$\mathrm{P}<0.05-$ significant

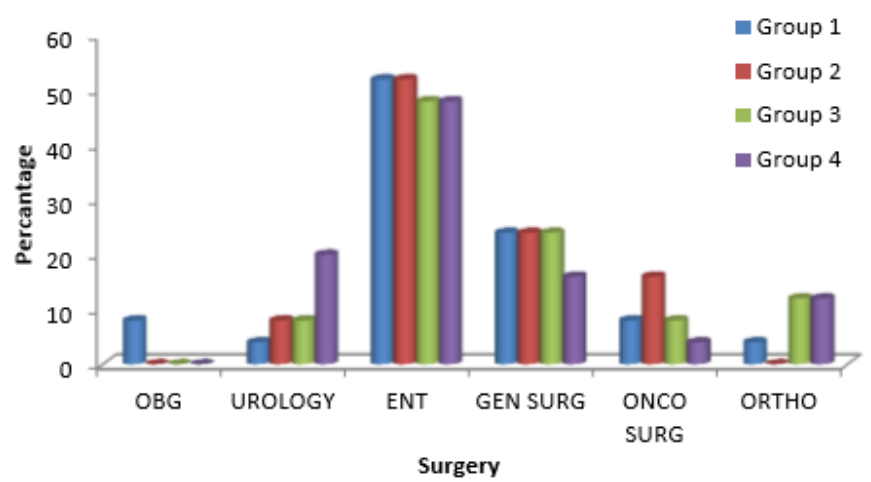

Figure 1: Types of surgery in four groups

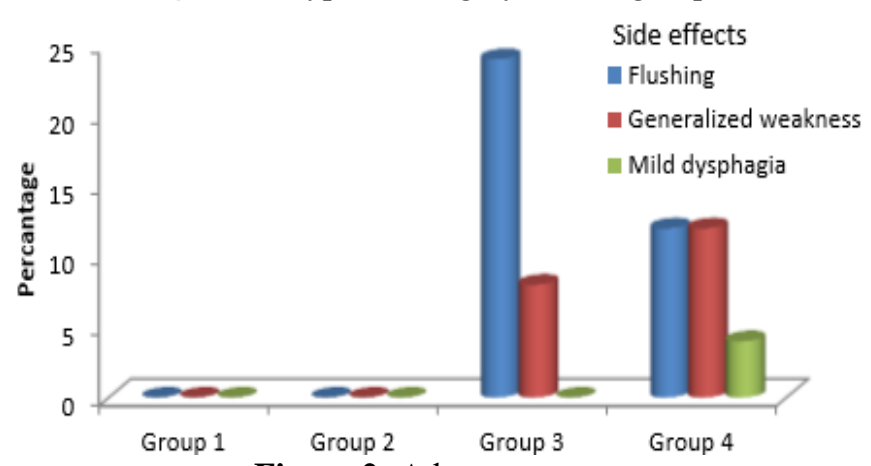

Figure 2: Adverse events

\section{Discussion}

Succinylcholine is a depolarizing muscle relaxant which has a faster onset and a short duration of action. But it is not an ideal muscle relaxant because of complications associated with its use including bradycardias, asystole, malignant hyperthermia and raised IOP (7).

There is a need for a non-depolarising muscle relaxant for faster onset of action but with minimal side effects. Vecuronium is one of the non-depolarising muscle relaxant of the aminosteroid group used for endotracheal intubation and muscle relaxation during surgery. It is a neuromuscular blocker of intermediate duration and is hemodynamically stable in most patients (1).
The specific sites or stages at which neuromuscular transmission is impaired seem to differ between magnesium and priming, which may cause the synergistic acceleration of the effects of non depolarizing neuromuscular blockers (8). So this study was undertaken to evaluate the onset of action, intubating conditions, duration of neuromuscular blockade with vecuronium as priming and the combination of magnesium pretreatment with vecuronium priming.

Magnesium sulphate is associated with a lower variance for vecuronium onset time compared with that in controls. The magnesium and prime group showed significantly smaller $\mathrm{SD}$ and variance compared with those in the magnesium group. Hence, the magnesium sulphate and priming combination not only facilitated the onset of neuromuscular blockade but also reduced the variability of onset time, providing a more predictable onset than with magnesium sulphate alone similar to previous studies().

In our study, we found that the magnesium and prime group (Group MV) had the shortest onset time 112.80 (s) \pm 19.89 $(\mathrm{p}<0.001)$ which was statistically significant, followed by magnesium group (Group M), where it was 128.40 \pm 25.27 . This was similar to the study done by $\mathrm{Kim} \mathrm{MH}$ et al (6), comparing rocuronium priming, magnesium pre-treatment and a combination of the two, found that the magnesium and prime group had the shortest onset time and best tracheal intubating conditions.

The onset of time of neuromuscular blockade in priming technique and magnesium pretreatment groups was statistically short as compared to the control (Group N) group. This finding is in concurrence with other studies $(5$, 9).

In our study, the duration of action was determined by the reappearance of 4 th twitch in minutes in four groups of patients studied. Intergroup comparison revealed $\mathrm{P}<0.001$. Indicating that duration of neuromuscular blockade was prolonged in patients who received magnesium sulphate. This was statistically significant compared to all the other three groups.

\section{Volume 4 Issue 11, November 2015}




\section{International Journal of Science and Research (IJSR) \\ ISSN (Online): 2319-7064}

Index Copernicus Value (2013): 6.14 | Impact Factor (2014): 5.611

We used the so-called "intubating dose" of vecuronium $(0.1 \mathrm{mg} / \mathrm{kg})$. With this dose we found a clinical duration of action of about $40 \mathrm{~min}$. However, after pretreatment with $\mathrm{MgSO} 4$ the duration of vecuronium block was nearly doubled. The rapid recovery of neuromuscular function after vecuronium contributes to its safety in clinical practice (10). Similar results were found in previous study where they investigated the interaction between magnesium sulphate and rocuronium $(9,11)$. The same was seen in the study done on children (12). They found the duration of neuromuscular bloackade in magnesium group was significantly prolonged.

In the study, by $\mathrm{Kim} \mathrm{MH}$ et al (6), comparing rocuronium priming, magnesium pre-treatment and a combination of the two methods, the duration of neuromuscular blockade was increased by $27 \%$ and $30 \%$ in the magnesium, and magnesium and prime groups, respectively. However, the increases were not statistically different between the groups, possibly due to smaller group size.

In our study, 6(24\%) patients in Group $M$ and $3(12 \%)$ patients in Group MV experienced flushing, 2(8\%) patients in Group M and 3(12\%) patients in Group MV experienced generalized weakness. One patient in Group MV experienced mild dysphagia. In our study these adverse effects were reported but did not require treatment or interruption of the magnesium sulphate infusion similar to the previous studies [6]. No adverse events such as difficulty with breathing or aspiration of gastric contents were observed after injection of the vecuronium priming dose. Vecuronium priming and magnesium pre-treatment did not result in any critical complications such as hypoxia, respiratory difficulty, or aspiration similar to the previous studies.

Our study has few limitations - 1. The sample size may be small. 2. The train of four stimulus was given every 30 seconds, so the onset of neuromuscular blockade was not detected very accurately.

\section{Conclusion}

Thus, in conclusion, pre-treatment with both magnesium sulphate and a priming dose of vecuronium provided faster onset of neuromuscular blockade and longer duration of neuromuscular blockade compared with magnesium sulphate pre-treatment or vecuronium priming alone without any critical adverse events.

\section{References}

[1] Tarbeeh GA,Othman MM. The pharmacodynamics of vecuronium in CRF: The impact of different priming doses. Renal Failure 2012 Aug; 34(7):827-33.

[2] Sang HK, Keum YS, Ki TJ. Effect of magnesium sulphate pre-treatment on onset and recovery characteristics of cisatracurium. Korean Journal Anaesthesiol. 2012 June; 62(6):518-23.

[3] $\mathrm{Wu} \mathrm{HL}$, Ye TH, Sun L. Effects of atracurium pretreatment with magnesium on speed of onset, duration, and recovery of neuromuscular blockade. Acta Academiae Medicinae Sinicae 2009;31:73-6.
[4] Rao MH, Venkataraman A, Malleswari R. Comparison of intubating conditions between rocuronium with priming and without priming: Randomized and double blind study. Indian J Anaesth. 2011 Sep-Oct; 55(5):494-8.

[5] Schmidt J, Irouschek A, Muenster T, Hemmerling TM, Albrecht S. A priming technique accelerates onset of neuromuscular blockade at the laryngeal adductor muscles. Canadian Journal of Anesthesia 2005; 52(1):50-4.

[6] Kim MH, Oh AY, Jeon YT, Hwang JW, Do SH. A randomised controlled trial comparing rocuronium priming, magnesium pre-treatment and a combination of the two methods. Anaesthesia 2012 July; 67(7):748-54.

[7] Feldman Stanley. Neuromuscular transmission, In: Miller RD, editor. Atlas of Anesthesia. Churchill Livingstone, 1998; Chapter 8, p.8.1-8.89.

[8] Viby-Mogenson J. Neuromuscular transmission. Wylie and Churchill Davidsonee - A Practice of Anaesthesia,6th ed, Edward-Arnold Publication, 2003; Chapter 8. P:129-33.

[9] Czarnetzki C, Lysakowski C, Elia N, Tramer MR. Time course of rocuronium induced neuromuscular block after pre-treatment with magnesium sulphate: a randomised study. Acta Anaesthesiol Scand. 2010; 54:299-306.

[10] Dale HH. The action of certain esters and ethers of choline and their relation to muscarine. J Pharmacol.1974; 6:147-90.

[11] Park SJ, Cho YJ, Oh JH, Hwang JW. Pretreatment of magnesium sulphate improves intubating conditions of rapid sequence tracheal intubation using alfentanil, propofol, and rocuronium - a randomized trial. Korean J Anesthesiol. 2013Sep; 65(3):221-7.

[12] Bock M, Haselmann L, Böttiger BW, Motsch J. Priming with rocuronium accelerates neuromuscular block in children. Canadian Journal of Anesthesia 2007; 54(7): 538-43.

\section{Author Profile}

Dr K B Nalini is serving as Assistant Professor, Department of Anaesthesiology, M S R Medical College, Bangalore, India.

Dr. Shazia Ambareen is serving as resident, Department of Anaesthesiology, M S R Medical College, Bangalore, India.

Dr. Mohan C V R is professor in Department of Anaesthesiology, M S R Medical College, Bangalore, India 